\title{
EFFICACY OF INTRATHECAL NEOSTIGMINE, CLONIDINE OR THEIR COMBINATION CO- ADMINISTERED WITH SPINAL BUPIVACAINE IN PATIENTS UNDERGOING LOWER LIMB ORTHOPAEDIC SURGERY
}

\author{
Purba Haldar1, Sushil Kumar Nayak2, Shibani Chakraborty33, Piyali Roychoudhury4, Joydeb Roy5
}

${ }^{1}$ Assistant Professor, Department of Anaesthesiology, CNMC and H, Kolkata.

${ }^{2}$ Associate Professor, Department of Anaesthesiology, CNMC and H, Kolkata.

${ }_{3}^{3}$ Postgraduate Trainee, Department of Anaesthesiology, CNMC and H, Kolkata.

${ }_{4}^{4}$ RMO-cum-Clinical Tutor, Department of Anaesthesiology, CNMC and H, Kolkata.

${ }_{5}^{5}$ Associate Professor, Department of Anaesthesiology, CNMC and H, Kolkata.

\begin{abstract}
BACKGROUND
ABSTRACT

The spinal administration of combination of $\alpha 2$ agonist, Clonidine and cholinesterase inhibitor Neostigmine along with bupivacaine is under clinical investigation for potential use in the perioperative period. Combination of both drugs in lower doses along with bupivacaine can produce adequate analgesia with less adverse effects.

Aims and Objectives- The purpose of the study is to evaluate the efficacy and safety of combining a lower dose of clonidine and neostigmine added with bupivacaine for providing better analgesia with less adverse effects in patients undergoing lower limb orthopaedic surgery.
\end{abstract}

\section{MATERIALS AND METHODS}

200 healthy patients of American Society of Anaesthesiologist's physical status I and II, aged between 50 to 55 years, weighing about 50 - $60 \mathrm{~kg}$, height 150 to $160 \mathrm{~cm}$, scheduled for lower limb Orthopaedic surgery under spinal anaesthesia were divided in four groups ( $\mathrm{n}=50)$. The Group B received 0.5\% Bupivacaine $12.5 \mathrm{mg}(2.5 \mathrm{~mL}$ ) with $0.5 \mathrm{~mL}$ normal saline; Group BN received $0.5 \%$ Bupivacaine $12.5 \mathrm{mg}(2.5 \mathrm{~mL})$ with $25 \mathrm{mcg}$ Neostigmine; Group BC received 0.5\% Bupivacaine $12.5 \mathrm{mg}(2.5 \mathrm{~mL})$ with $50 \mathrm{mcg}$ Clonidine; and Group BCN received 0.5\% Bupivacaine $12.5 \mathrm{mg}(2.5 \mathrm{~mL})$ with $12.5 \mathrm{mcg}$ Neostigmine and 25 mcg Clonidine respectively. Heart rate, non-invasive mean arterial blood pressure, respiratory rate, SPO2, onset of sensory and motor block, duration of sensory and motor block, analgesia, sedation level and any adverse effects were recorded at regular interval and the parameters were compared among different groups with appropriate statistical methods.

\section{RESULTS}

There was no significant statistical difference between the age, weight, height, ASA status of the patients included in study group (p $\leq 0.05$ ) and groups are comparable to each other in term of duration of surgery ( $p>0.05)$. Onset of sensory block was highly significant in Gr BCN, as p value $<0.001$. Onset of motor block was also significant in Gr BCN, as p value $<0.05$. When $\mathrm{Gr} B C$, BN and $\mathrm{BCN}$ were compared to Gr B, the duration of motor block was found significantly longer in all the three groups, as $\mathrm{p}$ value $<0.001$. When Gr BC, BN and BCN were compared to $\mathrm{Gr} B$, the duration of analgesia was found to be significantly prolonged in all three groups, as p value $<0.001$. When $\mathrm{Gr} \mathrm{BC}, \mathrm{BN}$ and $\mathrm{BCN}$ were compared to $\mathrm{Gr} \mathrm{B}$, the sedation score was found to be significantly prolonged in Gr BC and Gr BCN, as p value < 0.001. Mean arterial pressure of the patients of Gr BC, Gr BN and Gr BCN were compared to Gr B, it was found to be significantly lower at some particular point of time in Gr BCN, as p value $<0.001$. When pulse rate of the patients of $\mathrm{Gr} \mathrm{BC}, \mathrm{Gr} \mathrm{BN}$ and $\mathrm{Gr} \mathrm{BCN}$ were compared to $\mathrm{Gr} \mathrm{B}$, it was found to be significantly lower at some particular point of time in Gr BCN as p value $<0.001$. The requirement of rescue analgesic drug was more in Group B patients than any other groups.

\section{CONCLUSION}

With neostigmine and clonidine added with bupivacaine as an adjuvant in lower dose provides good haemodynamic stability, lesser adverse effects and good postoperative analgesia.

\section{KEYWORDS}

Spinal Anaesthesia, Bupivacaine, Clonidine, Neostigmine, Postoperative Analgesia.

HOW TO CITE THIS ARTICLE: Haldar P, Nayak SK, Chakraborty S, et al. Efficacy of intrathecal neostigmine, clonidine or their combination co-administered with spinal bupivacaine in patients undergoing lower limb orthopaedic surgery. J. Evolution Med. Dent. Sci. 2018;7(05):626-631, DOI: 10.14260/jemds/2018/142

'Financial or Other Competing Interest': None.

Submission 24-10-2017, Peer Review 11-01-2018,

Acceptance 18-01-2018, Published 29-01-2018.

Corresponding Author:

Dr. Purba Haldar,

Flat L-3, Block IV, Swabhumi Residency,

P-12, Motijheel Avenue, Kolkata-700074.

E-mail: purbahaldar@gmail.com

DOI: $10.14260 /$ jemds $/ 2018 / 142$

(c) (i) $\ominus$

\section{BACKGROUND}

Spinal anaesthesia with Bupivacaine is one of the most popular regional anaesthesia techniques in patients undergoing lower limb orthopaedic surgery. ${ }^{1}$ But with this technique, adequate postoperative analgesia is not maintained in all the patients. Spinal administration of Clonidine, an $\alpha 2$ adrenergic agonist, provides excellent analgesia without the risk of significant motor block or respiratory depression. ${ }^{2}$ Intrathecal administration of cholinesterase inhibitor, neostigmine administered 
intrathecally in lower doses has been shown to produce analgesia without any adverse effects in lower limb orthopaedic surgery. ${ }^{3}$ The spinal administration of combination of $\alpha 2$ agonist and neostigmine along with bupivacaine is under clinical investigation for potential use in the perioperative period. Addition of neostigmine enhances intrathecal clonidine induced analgesia and counteracts clonidine induced hypotension. ${ }^{4}$ But the clinical utility of the study was limited by adverse effects like motor block, dizziness, nausea and vomiting which are solely related to the dose of individual drug. ${ }^{5}$ The purpose or objective of the study is to evaluate the efficacy and safety of combining a lower dose of clonidine and neostigmine with bupivacaine for providing better analgesia with less adverse effects in patients undergoing lower limb orthopaedic surgery.

\section{MATERIALS AND METHODS}

After obtaining the Institutional Ethical Committee clearance and written informed consent obtained in their own language, 200 patients of American Society of Anesthesiologists physical status I and II, aged between 50 to 55 years, weighing about $50-60 \mathrm{~kg}$, height 150 to $160 \mathrm{~cm}$, scheduled for lower limb Orthopaedic surgery under spinal anaesthesia were included in this prospective, randomised, double blind controlled study. Patients with hypertension, diabetes mellitus, cardiac disease, bleeding diathesis, hypovolemia, neurological disorder and known allergy to study drugs were excluded from our study. In the preoperative visit, all the patients were examined thoroughly and details of Visual Analogue Scale (VAS $0=$ no pain to VAS $10=$ severe pain) were explained on the day before surgery. Those patients who could not follow the VAS score were excluded from the study. Patients were advised overnight fasting, none of them received any premedication. After entering the holding area, patient's vital parameters such as pulse rate, blood pressure, respiratory rate, ECG and SpO2 were recorded as baseline by a non-invasive monitor. After intravenous cannulation, patients were preloaded with Lactated Ringers' solution $10 \mathrm{~mL} / \mathrm{kg}$ body weight. Spinal anaesthesia was administered under full aseptic condition with 25-gauge Quincke's spinal needle at Lumbar 3 - 4 or Lumbar 4 - 5 interspace using a midline approach in sitting position. Assuming $\mathrm{p}$ value $<0.05$ to be significant and considering effect to be two sided, we get $\mathrm{Z} \alpha=1.96$; assuming power of study to be $80 \%$ we get $Z 1-\beta=0.84$; considering an effect size (Difference in VAS score between the groups) of 1.5 to be statistically significant we get $n>2(Z \alpha+Z 1-\beta) 2 x$ $\mathrm{SD} 2 / \mathrm{d} 2$ we get $\mathrm{n}=44$ in each group. Hence, minimum 44 patients to be taken in each group. Therefore, to account for probable dropouts, a number of 50 patients in each group was proposed. We took total 200 patients for our study patients and they were randomly allocated into four groups with equal number $(n=50)$ by using computer generated random numbers. The Group B received 0.5\% Bupivacaine $12.5 \mathrm{mg}(2.5 \mathrm{~mL})$ with $0.5 \mathrm{~mL}$ normal saline; Group BN received $0.5 \%$ Bupivacaine $12.5 \mathrm{mg}(2.5 \mathrm{~mL})$ with $25 \mathrm{mcg}$ Neostigmine; Group BC received 0.5\% Bupivacaine $12.5 \mathrm{mg}$ $(2.5 \mathrm{~mL})$ with $50 \mathrm{mcg}$ Clonidine; and Group BCN received $0.5 \%$ Bupivacaine $12.5 \mathrm{mg}(2.5 \mathrm{~mL})$ with $12.5 \mathrm{mcg}$ Neostigmine and $25 \mathrm{mcg}$ Clonidine respectively. The preparation, labelling of study drugs in a syringe and postoperative assessment were done by anaesthesiologists who were not aware of the study. Total volume of the study drug was $3 \mathrm{~mL}$ and preservative free. After placement of the study drug intrathecally, patients were immediately placed in supine position. Blood pressure were monitored every 5 minutes for first 30 minutes and then every 15 minutes throughout the surgery. Patients were monitored continuously with ECG, SPO2 and respiratory rate. Supplemental oxygen @ 2 Lt/min and intravenous Midazolam $2 \mathrm{mg}$ were administered to all patients. Decrease in systolic blood pressure $>30 \%$ below baseline or $<90$ mmHg was treated with Phenylephrine. Bradycardia of < $50 /$ min was treated with Atropine. Time of placement of the study drug into spinal space was noted. The onset of sensory analgesia was defined as loss of sensation to bilateral pinprick injury in anterior axillary line, which was tested every two minutes in the initial 15 minutes and then every five minutes throughout the duration of surgery. Time of maximal cephalad spread was defined as time from onset of analgesia up to time of highest level of sensory analgesia achieved. Duration of sensory analgesia was defined as two segment regression of analgesia from the highest level of analgesia achieved. Duration of motor block was recorded by Modified Bromage Scale from the time of drug administration to the time when the patients could lift the leg. After completion of the surgery, the patients were transferred to the recovery room. Heart rate, non-invasive blood pressure, respiratory rate, $\mathrm{SpO2}$, analgesia and sedation level were recorded at regular interval. VAS was used to assess the amount of pain at rest and with movement (side-to-side) at $30,60,120$ minutes and every 30 minutes in early postoperative period and every 2 hours in late postoperative period. Diclofenac Sodium was administered as rescue analgesic when VAS is $\geq 4$.

Throughout the procedure any untoward effects like nausea, vomiting, itching and shivering were treated with medications.

\section{Statistical Methods}

Categorical variables will be expressed as number of patients and percentage of patients and compared across the groups Pearson's Chi-square test for Independence of Attributes/ Fisher's Exact Test as appropriate.

Continuous variables will be expressed as Mean \pm Standard Deviation and compared across groups using unpaired ' $\mathrm{t}$ ' test/ One-Way ANOVA if the data follows normal distribution and Mann-Whitney U test/ Kruskal-Wallis test if the data does not follow normal distribution.

The statistical software SPSS version 20 will be used for the analysis. An alpha level of $5 \%$ has been taken, i.e. if any ' $p$ ' value is less than 0.05 it will be considered as significant.

\section{RESULTS}

There was no significant statistical difference between the age, weight, height and ASA status of the patients included in the study group ( $\mathrm{p} \leq 0.05$ ). There was no statistically significant difference in duration of surgery among the study groups and groups are comparable to each other in terms of duration of surgery ( $p>0.05$ ). Mean onset of sensory block was $3.1 \pm 0.6 \mathrm{~min}, 2.9 \pm 0.2 \mathrm{~min}, 2.9 \pm 0.2 \mathrm{~min}$ and $2.1 \pm 0.3$ min in Gr B, BC, BN and BCN respectively. Regarding height of sensory block, upto T4 sensory segment block was achieved in 4, 9, 8 and 8 number of patients in Gr B, BC, BN and BCN 
respectively. Upto T5 segment level was achieved in 10, 11, 8 and 10 number of patients in $\mathrm{Gr} B, \mathrm{BC}, \mathrm{BN}$ and $\mathrm{BCN}$ respectively. Upto $\mathrm{T} 6$ segment level was achieved in 12, 10, 12 and 13 numbers of patients in $\mathrm{Gr} B, \mathrm{BC}, \mathrm{BN}$ and BCN respectively. Upto $\mathrm{T} 7$ segment level was achieved in 12,10 , 12 and 10 number of patients in Gr B, BC, BN and BCN respectively. Upto $\mathrm{T} 8$ segment was achieved in $12,10,10$ and 10 patients of Gr B, BC, BN and BCN respectively. Mean onset of motor block was $3.6 \pm 0.1 \mathrm{~min}, 3.5 \pm 0.3 \mathrm{~min}, 3.5 \pm 0.4 \mathrm{~min}$ and $2.9 \pm 0.9$ min in $\mathrm{Gr} \mathrm{B}, \mathrm{BC}, \mathrm{BN}$ and $\mathrm{BCN}$ respectively. Mean duration of motor block were $155.6 \pm 12.7 \mathrm{~min}, 201.7 \pm 13.7$ min, $210.8 \pm 12.8 \mathrm{~min}$ and $312.9 \pm 09.8 \mathrm{~min}$ in $\mathrm{Gr} \mathrm{B}, \mathrm{BC}, \mathrm{BN}$ and $\mathrm{BCN}$ respectively. When $\mathrm{Gr} \mathrm{BC}, \mathrm{BN}$ and $\mathrm{BCN}$ were compared to $\mathrm{Gr} \mathrm{B}$, the duration of motor block was found significantly longer in all the three groups as $p$ value $<0.001$. Mean duration of analgesia was 187.9.5 $\pm 18.6 \mathrm{~min}, 234.8 \pm$ $16.6 \mathrm{~min}, 245.8 \pm 11.4 \mathrm{~min}$ and $338.7 \pm 10.8 \mathrm{~min}$ in $\mathrm{Gr} \mathrm{B}, \mathrm{BC}$, $\mathrm{BN}$ and $\mathrm{BCN}$ respectively. When $\mathrm{Gr} \mathrm{BC}, \mathrm{BN}$ and $\mathrm{BCN}$ were compared to $\mathrm{Gr} \mathrm{B}$, the duration of analgesia was found to be significantly prolonged in all three groups as $p$ value $<0.001$. Mean pulse rate and blood pressure at different times were comparable in four different groups. Number of rescue analgesic required in first 24 hours was $14,12,12$ and 11 in Gr B, BC, BN and BCN respectively. Mean sedation score was $1.9 \pm 0.9,2.7 \pm 0.6,2.1 \pm 0.4$ and $2.2 \pm 0.7$ in $\mathrm{Gr} \mathrm{B}, \mathrm{BC}, \mathrm{BN}$ and $\mathrm{BCN}$ respectively. When $\mathrm{Gr} \mathrm{BC}, \mathrm{BN}$ and $\mathrm{BCN}$ were compared to $\mathrm{Gr} \mathrm{B}$, the sedation score was found to be significantly prolonged in all three groups as $p$ value $<0.001$. Rescue analgesic drug requirement were more in patients of group $B$ in comparison to patients of other three groups and it was statistically significant as $p$ value $<0.001$. VAS score was comparable among all four groups in earlier point of time. In the postoperative period patients belonging to $\mathrm{Gr} \mathrm{BC}$, $\mathrm{Gr} \mathrm{BN}$ and Gr BCN had the lower VAS score than the patients belonging to $\mathrm{Gr}$ B. VAS score were comparable among $\mathrm{Gr} \mathrm{BC}$, $\mathrm{BN}$ and $\mathrm{BCN}$ in early postoperative period. Regarding adverse effects, nausea was found in 10 and 6 patients in $\mathrm{Gr}$ BN and Gr BCN respectively. Vomiting was observed in 7 and 6 patients in Gr BN and Gr BCN respectively. Only 3 patients of Gr BC complained of dry mouth. Itching was not found in any patient. Shivering was present in 5, 6, 4 and 3 patients in $\mathrm{Gr} B$, $\mathrm{BC}, \mathrm{BN}$ and BCN respectively. No patient of any group suffered from significant hypotension or bradycardia.

\begin{tabular}{|c|c|c|c|}
\hline Groups & Age (Years) & Weight (kg) & Height (cm) \\
\hline Gr B & $53.3 \pm 82$ & $58.1 \pm 03$ & $155.7 \pm 4.4$ \\
\hline Gr BC & $52.2 \pm 9.1$ & $57.6 \pm 06$ & $156.5 \pm 3.2$ \\
\hline Gr BN & $54.1 \pm 01$ & $58,7 \pm 17$ & $156.7 \pm 5.2$ \\
\hline Gr BCN & $53,5 \pm 71$ & $57.8 \pm 32$ & $155.3 \pm 1.8$ \\
\hline \multicolumn{4}{|c|}{ Table 1 } \\
\hline
\end{tabular}

Table 1 shows the distribution of age, weight and height in four study groups. There are no statistically significant difference in age, weight and height among the study groups as $p$ value was $>0.05$ and groups were comparable to each other.

\begin{tabular}{|c|c|c|}
\hline Groups & ASA I & ASA II \\
\hline Gr B & 25 & 25 \\
\hline Gr BC & 24 & 26 \\
\hline Gr BN & 26 & 24 \\
\hline Gr BCN & 24 & 26 \\
\hline \multicolumn{3}{|c|}{ Table 2 } \\
\hline
\end{tabular}

Table 2 shows ASA classification in four study groups. There was no statistically significant differences in ASA classifications among study groups according to Chi-square test as $p$ value was $>0.05$.

\begin{tabular}{|c|c|c|c|c|c|}
\hline Groups & T4 & T5 & T6 & T7 & T8 \\
\hline Gr B & 4 & 10 & 12 & 12 & 12 \\
\hline Gr BC & 9 & 11 & 10 & 10 & 10 \\
\hline Gr BN & 8 & 8 & 12 & 12 & 10 \\
\hline Gr BCN & 8 & 10 & 13 & 10 & 10 \\
\hline \multicolumn{6}{|c|}{ Table 3. Height of Sensory Block (Segment) } \\
\hline
\end{tabular}

Table 3 shows height of sensory block in four study groups. There was statistical difference in height of sensory block among Group BC, Gr BN and Gr BCN when they were compared to $\mathrm{Gr} \mathrm{B}$ and the $\mathrm{P}$ value $<0.001$.

\begin{tabular}{|c|c|c|}
\hline Groups & $\begin{array}{c}\text { Onset of Sensory } \\
\text { Block in Minutes }\end{array}$ & $\begin{array}{c}\text { Onset of Motor } \\
\text { Block in Minutes }\end{array}$ \\
\hline Gr B & $3.1 \pm 0.6$ & $3.6 \pm 0.1$ \\
\hline Gr BC & $2.9 \pm 0.2$ & $3.5 \pm 0.3$ \\
\hline Gr BN & $2.9 \pm 0.2$ & $3.5 \pm 0.4$ \\
\hline Gr BCN & $2.1 \pm 0.3$ & $2.9 \pm 0.9$ \\
\hline \multicolumn{3}{|c|}{ Table 4. Onset of Sensory Block and Onset of Motor Block in } \\
Minutes \\
\hline
\end{tabular}

Table 4 shows the onset of sensory block and motor block in four study groups. Onset of sensory block was highly significant in Gr BCN, as p value $<0.001$. Onset of motor block was also significant in $\mathrm{Gr} \mathrm{BCN}$, as $\mathrm{p}$ value $<0.05$.

\begin{tabular}{|c|c|c|c|c|}
\hline Groups & $\begin{array}{c}\text { Duration of } \\
\text { Surgery }\end{array}$ & $\begin{array}{c}\text { Duration of } \\
\text { Sensory } \\
\text { Block }\end{array}$ & $\begin{array}{c}\text { Duration of } \\
\text { Motor } \\
\text { Block }\end{array}$ & $\begin{array}{c}\text { Duration of } \\
\text { Analgesia }\end{array}$ \\
\hline \multirow{2}{*}{ Gr B } & $120.2 \pm$ & $167.4 \pm$ & $155.6 \pm$ & $187.9 \pm$ \\
& 18.3 & 15.1 & 12.7 & 18.6 \\
\hline \multirow{2}{*}{ Gr BC } & $122.4 \pm$ & $220.2 \pm$ & $201.7 \pm$ & $234.8 \pm$ \\
& 15.2 & 27.2 & 13.7 & 16.6 \\
\hline \multirow{2}{*}{ Gr BN } & $120.5 \pm$ & $235.2 \pm$ & $210.8 \pm$ & $245.8 \pm$ \\
& 14.8 & 22.1 & 12.8 & 11.4 \\
\hline \multirow{2}{*}{ Gr BCN } & $123.1 \pm$ & $330.5 \pm$ & $312.9 \pm$ & $338.7 \pm$ \\
& 02.3 & 38.9 & 09.8 & 10.8 \\
\hline \multicolumn{5}{|c|}{ Table 5. Duration of Surgery, Duration of Sensory Block } \\
(Two Segment Regression from Highest Level), Duration of \\
Motor Block and Duration of Analgesia \\
\hline
\end{tabular}

Table 5 shows that there is no statistically significant difference in duration of surgery among the study groups, as $\mathrm{p}$ value is $>0.05$. Hence, the groups are comparable to each other. When Gr BC, Gr BN and Gr BCN were compared to Gr B, the duration of sensory block, duration of motor block and duration of analgesia were found to be significantly longer as $\mathrm{p}$ value $<0.001$.

\begin{tabular}{|c|c|c|c|c|}
\hline Time & Gr B & Gr BC & Gr BN & Gr BCN \\
\hline \multirow{2}{*}{ Baseline } & $82.2 \pm$ & $80.51 \pm$ & $81.6 \pm$ & $82.4 \pm$ \\
& 3.21 & 2.25 & 5.71 & 3.31 \\
\hline \multirow{2}{*}{5 mins } & $76.3 \pm$ & $72.82 \pm$ & $74.68 \pm$ & $74.24 \pm$ \\
& 5.32 & 1.45 & 1.12 & 4.56 \\
\hline \multirow{2}{*}{10 mins } & $76.5 \pm$ & $70.68 \pm$ & $75.32 \pm$ & $74.46 \pm$ \\
& 3.90 & 2.20 & 3.90 & 4.82 \\
\hline \multirow{2}{*}{15 mins } & $78.6 \pm$ & $68.68 \pm$ & $76.86 \pm$ & $72.86 \pm$ \\
& 2.21 & 1.34 & 6.41 & 4.46 \\
\hline \multirow{2}{*}{20 mins } & $72.5 \pm$ & $62.60 \pm$ & $78.86 \pm$ & $70.78 \pm$ \\
& 3.53 & 2.23 & 2.26 & 2.20 \\
\hline
\end{tabular}




\begin{tabular}{|c|c|c|c|c|}
\hline \multirow{2}{*}{25 mins } & $72.65 \pm$ & $60.68 \pm$ & $70.66 \pm$ & $66.76 \pm$ \\
& 2.37 & 5.52 & 1.12 & 2.24 \\
\hline \multirow{2}{*}{30 mins } & $70.64 \pm$ & $64.68 \pm$ & $70.46 \pm$ & $68.68 \pm$ \\
& 1.10 & 4.32 & 2.24 & 1.12 \\
\hline \multirow{2}{*}{45 mins } & $72.65 \pm$ & $60.60 \pm$ & $70.65 \pm$ & $60.68 \pm$ \\
& 4.43 & 6.12 & 8.10 & 2.24 \\
\hline \multirow{2}{*}{60 mins } & $76.46 \pm$ & $64.56 \pm$ & $70.46 \pm$ & $62.68 \pm$ \\
& 6.2 & 2.24 & 6.62 & 1.12 \\
\hline \multirow{2}{*}{75 mins } & $78.32 \pm$ & $60.43 \pm$ & $71.21 \pm$ & $66.56 \pm$ \\
& 5.4 & 8.21 & 5.56 & 5.60 \\
\hline \multirow{2}{*}{90 mins } & $78.60 \pm$ & $62.12 \pm$ & $70.56 \pm$ & $60.66 \pm$ \\
& 3.2 & 2.20 & 2.24 & 5.62 \\
\hline \multirow{2}{*}{105 mins } & $81.78 \pm$ & $64.12 \pm$ & $70.56 \pm$ & $62.78 \pm$ \\
& 6.6 & 1.20 & 5.66 & $4.42^{*}$ \\
\hline \multirow{2}{*}{180 mins } & $82.56 \pm$ & $66.34 \pm$ & $76.64 \pm$ & $62.32 \pm$ \\
& 3.21 & 8.64 & 3.46 & 8.86 \\
\hline \multirow{2}{*}{270 mins } & $84.12 \pm$ & $69.89 \pm$ & $78.80 \pm$ & $64.20 \pm$ \\
& 1.12 & 5.68 & 2.24 & $5.54^{*}$ \\
\hline \multirow{2}{*}{390 mins } & $86.68 \pm$ & $72.65 \pm$ & $80.89 \pm$ & $68.64 \pm$ \\
& 3.20 & 8.64 & 4.42 & 6.32 \\
\hline \multicolumn{5}{|c|}{ Table 6. Mean Arterial Pressure at Different Time } \\
\hline
\end{tabular}

Table 6 shows when mean arterial pressure of the patients of $\mathrm{Gr} \mathrm{BC}, \mathrm{Gr} \mathrm{BN}$ and $\mathrm{Gr} \mathrm{BCN}$ were compared to $\mathrm{Gr} \mathrm{B}$, it was found to be significantly lower at some particular point of time, as $p$ value $<0.001$.

\begin{tabular}{|c|c|c|c|c|}
\hline Time & Gr B & Gr BC & Gr BN & Gr BCN \\
\hline Baseline & $84.2 \pm 4.2$ & $85.6 \pm 3.2$ & $84.4 \pm 2.2$ & $84.6 \pm 2.8$ \\
\hline 5 mins & $82.6 \pm 4.6$ & $80.8 \pm 2.2$ & $84.3 \pm 4.2$ & $82.6 \pm 2.6$ \\
\hline 10 mins & $78.8 \pm 6.8$ & $78.8 \pm 2.0$ & $80.6 \pm 6.6$ & $80.8 \pm 1.8$ \\
\hline 15 mins & $77.4 \pm 6.8$ & $76.6 \pm 2.2$ & $80.8 \pm 6.4$. & $78.5 \pm 4.8$ \\
\hline 20 mins & $72.6 \pm 6.4$ & $68.8 \pm 2.4$ & $72.6 \pm 6.2$ & $76.6 \pm 4.2$ \\
\hline 25 mins & $70.4 \pm 6.8$ & $70.8 \pm 2.2$ & $72.4 \pm 2.2$ & $62.4 \pm 6.6$ \\
\hline 30 mins & $74.5 \pm 5.6$ & $68.6 \pm 2.4$ & $70.6 \pm 2.4$ & $68.6 \pm 6.8$ \\
\hline 45 mins & $76.8 \pm 4.6$ & $66.6 \pm 6.2$ & $72.6 \pm 2.2$ & $66.6 \pm 7.2$ \\
\hline 60 mins & $72.8 \pm 5.4$ & $60.5 \pm 5.8$ & $70.8 \pm 1.2$ & $62.6 \pm 3.4$ \\
\hline 75 mins & $78.4 \pm 4.6$ & $60.6 \pm 4.6 *$ & $76.8 \pm 4.8$ & $60.8 \pm 2.2^{*}$ \\
\hline 90 mins & $82.6 \pm 8.2$ & $58.6 \pm 4.4$ & $76.6 \pm 4.2$ & $62.2 \pm 1.2$ \\
\hline 105 mins & $84.6 \pm 6.2$ & $58.2 \pm 4.2$ & $72.4 \pm 2.4$ & $58.4 \pm 3.4$ \\
\hline 180 mins & $88.8 \pm 4.6$ & $66.4 \pm 4.2$ & $70.6 \pm 2.2$ & $60.4 \pm 4.2^{*}$ \\
\hline 270 mins & $90.8 \pm 2.4$ & $68.6 \pm 4.6$ & $78.7 \pm 4.2$ & $62.8 \pm 5.6$ \\
\hline 390 mins & $84.6 \pm 2.2$ & $70.8 \pm 2.2$ & $78.8 \pm 4.2$ & $64.2 \pm 5.2$ \\
\hline \multicolumn{5}{|c|}{ Table 7. Pulse Rate at Different Time } \\
\hline
\end{tabular}

$* \mathrm{P}<0.001$

Table 7 shows that when pulse rate of the patients of $\mathrm{Gr}$ $\mathrm{BC}, \mathrm{Gr} \mathrm{BN}$ and Gr BCN were compared to Gr B, it was found to be significantly lower at some particular point of time in $\mathrm{Gr}$ BCN as $p$ value $<0.001$.

\begin{tabular}{|c|c|}
\hline Groups & $\begin{array}{c}\text { Average Number of Analgesic Dose } \\
\text { Required in 24 Hours }\end{array}$ \\
\hline Gr B & 4 \\
\hline Gr BC & 2 \\
\hline Gr BN & 2 \\
\hline Gr BCN & 2 \\
\hline \multicolumn{2}{|c|}{ Table 8. Number of Analgesic Dose in 24 Hours } \\
\hline
\end{tabular}

Table shows that the requirement of rescue analgesic drug was more in Group B patients than any other groups.

\begin{tabular}{|c|c|c|c|c|}
\hline Time & Gr B & Gr BC & Gr BN & Gr BCN \\
\hline 60 mins & 0 & 0 & 0 & 0 \\
\hline 90 mins & 0 & 0 & 0 & 0 \\
\hline 120 mins & 0 & 0 & 0 & 0 \\
\hline 150 mins & 2.2 & 0 & 0 & 0 \\
\hline 180 mins & 2.4 & 0 & 0 & 0 \\
\hline 210 mins & 3.1 & 0 & 1.9 & 1.8 \\
\hline 240 mins & 3.6 & 2.1 & 2.1 & 2.5 \\
\hline 270 mins & 4.1 & 2.3 & 2.3 & 3.2 \\
\hline 300 mins & 4.2 & 3.8 & 3.1 & 3.6 \\
\hline 330 mins & 5.1 & 4.6 & 4.3 & 3.8 \\
\hline 360 mins & 5.1 & 4.8 & 4.6 & 4.1 \\
\hline
\end{tabular}

Table 9. Average VAS Score in the Patients of Four Different Groups at Different Point of Time

VAS score was comparable among all four groups in earlier point of time. In the postoperative period, patients belonging to $\mathrm{Gr} \mathrm{BC}, \mathrm{Gr} \mathrm{BN}$ and $\mathrm{Gr} \mathrm{BCN}$ had the lower VAS score than the patients belonging to Gr B. VAS score were comparable among $\mathrm{Gr} \mathrm{BC}, \mathrm{BN}$ and $\mathrm{BCN}$ in early postoperative period.

\begin{tabular}{|c|c|}
\hline Groups & Mean \pm SD \\
\hline Gr B & $1.9 \pm 0.9$ \\
\hline Gr BC & $2.7 \pm 0.6$ \\
\hline Gr BN & $2.1 \pm 0.4$ \\
\hline G BCN & $2.2 \pm 0.7$ \\
\hline \multicolumn{2}{|c|}{ Table 10. Sedation Score } \\
\hline
\end{tabular}

Sedation score of $\mathrm{Gr}$ BC, Gr BN and Gr BCN were compared to $\mathrm{Gr} B$. The sedation score was found to be significantly more in $\mathrm{Gr} \mathrm{BC}$ and $\mathrm{Gr} \mathrm{BCN}$, as p value $<0.001$.

\section{DISCUSSION}

Neuroaxial drug administered as adjuvant to local anaesthetic drug have additive or synergistic actions. Optimum clinical outcome results from combining these drugs to improve the efficacy through positive analgesic interactions, but also to reduce side effects consecutive to the administration of high doses of single drug. Clonidine binding to $\alpha 2$ adrenergic receptors in the spinal cord dorsal horn inhibits release of substance $\mathrm{P}$ and produce analgesia. Spinal clonidine also increases the level of acetylcholine in the cerebrospinal fluid. Eisenach et al in 1996 studied the variety of different action of clonidine including the ability to potentiate the effect of local anaesthetic drug. ${ }^{6}$ Intrathecal clonidine is being exclusively evaluated as an alternative to neuroaxial opioids for control of pain and proven to be a potent analgesic, free of some of the opioid related side effects. ${ }^{7}$ Neostigmine prevents breakdown of an endogenous spinal neurotransmitter acetylcholine within the spinal cord. ${ }^{8}$ Acetylcholine binds to muscarinic and nicotinic receptor of the spinal cord and stimulates nitric oxide synthesis to produce analgesia. ${ }^{9}$ Both drugs possess a common mechanism of action mediated through acetylcholine release and their interaction can be beneficial to enhance analgesia. ${ }^{10}$ Haemodynamic advantage in the combination of clonidine and neostigmine also exists. Spinal clonidine decreases sympathetic outflow in the spinal cord intermediolateral cell column, whereas neostigmine, through an enhanced acetylcholine release in preganglionic sympathetic neurons increases sympathetic outflow. The incidence and severity of adverse effect from intrathecal neostigmine appears to be affected by dose, 11 method of 
administration and baricity of solution. These effects in human are consistent in animals.

Spinal neostigmine apparently activates descending pain inhibitory system that rely on a spinal cholinergic interneuron, probably exacerbating a cholinergic tonus that is already activated during the postoperative period 12 and seems to be extremely efficient for alleviating somatic pain. Hood and David D5,13 in 1996 in their study of interaction between intrathecal neostigmine and epidural clonidine in human volunteers showed that the combination of neostigmine and clonidine resulted in an additive enhancement of analgesia, but no enhancement of side effects of each drug and reduction in clonidine induced hypotension. Chan Jong Chung and Jim Su Kin ${ }^{14}$ have showed the efficacy of intrathecal neostigmine, morphine and their combination for post-caesarean section. Intrathecal neostigmine 25 microgram with morphine did not affect the characteristics of spinal anaesthesia, maternal blood pressure and heart rate or foetal status, but it produces 6 hours analgesia and reduced analgesic consumption over 24 hours.

Pan PM and Huang CT et al in their study in 1998 showed that combination of 150 micrograms intrathecal clonidine and 50 micrograms of neostigmine provided longer postsurgical analgesia than either drug used alone. This combination also produced significantly more adverse effect of prolonged motor block, nausea and vomiting. Owen MD and Ozsarac 0 et al ${ }^{15}$ in 2000 studied that low-dose clonidine (30 $\mathrm{mcg}$ ) and neostigmine (10 $\mathrm{mcg}$ ) prolonged the duration of intrathecal bupivacaine-fentanyl labour analgesia. D Kaushal and V Singh ${ }^{16}$ in 2009 showed that co-administration of neostigmine with bupivacaine prolong the duration of surgical analgesia after a single caudal injection, thus allowing single caudal injection to be recommended for surgery lasting more than 4 hours. Mamta Harjai and Girish Chandra et al 17 performed a comparative study of two different doses of neostigmine co-administered with lignocaine for postoperative analgesia and sedation in 2010. They concluded that co-administration of epidural neostigmine and lignocaine appears to be an useful technique for postoperative analgesia, as it increases the duration of analgesia and provides desirable sedation at the same time. A clinical study of perioperative effectiveness of adjuvant neostigmine with intrathecal bupivacaine for lower abdominal surgery conducted by Yoganarashima $\mathrm{N}$ et al 18 in 2012 showed that in a dose of $50 \mathrm{mcg}$ neostigmine used intrathecally provide adequate postoperative analgesia and is not associated with any significant haemodynamic disturbances or respiratory depression. In 2016, Pandey V et al also concluded that administration of intrathecal neostigmine in dose of $50 \mu \mathrm{g}$ as an adjuvant to bupivacaine produces haemodynamically stable analgesia with minimal side effects. Medge D et al also found that the combination of clonidine and neostigmine increased the duration of labour analgesia by $83 \%$ when added to IT $\mathrm{BF}$, but was associated with more nausea. Multiple drug combinations may be useful in extending labour analgesia as part of the CSE technique.

Present study was undertaken to compare the perioperative and postoperative analgesic efficacy as well as any untoward effects of clonidine and neostigmine. The result of our study has shown that the addition of either $50 \mathrm{mcg}$ clonidine and $25 \mathrm{mcg}$ neostigmine individually or their combination added in lower dose $(25$ mcg clonidine +12.5 mcg neostigmine) as an adjuvant with bupivacaine in spinal anaesthesia not only prolong the duration of analgesia, but also causes faster onset compared to established time of onset of sensory analgesia with bupivacaine alone. Addition of these two adjuvants in lower dose with bupivacaine promotes haemodynamic stability during intraoperative period.

\section{CONCLUSION}

In conclusion, the present study showed that combining intrathecal clonidine (25 mcg) and neostigmine $(12.5 \mathrm{mcg})$ in lower doses shortened the onset of bupivacaine induced spinal anaesthesia and prolong duration of postoperative analgesia, compared with either drug alone to bupivacaine. The incidence of postoperative nausea and vomiting increased with intrathecal neostigmine. Intrathecal clonidine causes more sedation. With neostigmine and clonidine added with bupivacaine as an adjuvant in lower dose provides good haemodynamic stability, lesser adverse effects and good postoperative analgesia.

\section{REFERENCES}

[1] Morgan GE, Mikhail MS, Murray MJ, et al. Clinical anaesthesiology. $4^{\text {th }}$ edn. New York, NY, USA: Lange 2002.

[2] Sethi BS, Samuel M, Sreevastava D. Efficacy of analgesic effects of low dose intrathecal clonidine as adjuvant to bupivacaine. Indian $\mathrm{J}$ Anesth 2007;51(5):415-9.

[3] Lauretti GR, Mattos AL, Reis MP, et al. Intrathecal neostigmine for post-operative analgesia after orthopaedic surgery. J Clin Anesth 1997;9(6):473-7.

[4] Pan PM, Huang CT, Wei TT, et al. Enhancement of analgesic effect of intrathecal neostigmine and clonidine on bupivacaine spinal anesthesia. Regional Anesthesia and Pain Medicine 1998;23(1):49-56.

[5] Hood DD, Mallak KA, Eisenach JC, et al. Interaction between intrathecal neostigmine and epidural clonidine in human volunteers. Anaesthesiology 1996;85(2):315-25.

[6] Eisenach JC, De Cock M, Klimscha W. Alpha 2 adrenergic agonists for regional anesthesia: a clinical review of clonidine (1984-1995). Anaesthesiology 1996;85(3):655-74.

[7] Shidhaye RV, Shah BB, Joshi SS, et al. Comparison of clonidine and fentanyl as an adjuvant to intrathecal bupivacaine for spinal anaesthesia and postoperative analgesia in patients undergoing caesarian section. Sri Lankan J Anaesthesiol 2013;22:15-20.

[8] Bartolini A, Ghelardini C, Fantetti L, et al. Role of muscarinic receptor subtypes in central antinociception. Br J Pharmacology 1992;105(1):7782.

[9] Iwamoto ET, Marion L. Characterization of the antinociception produced by intrathecally administered muscarinic agonists in rats. $\mathrm{J}$ of Pharmacol Exp Therapy 1993;266(1):329-38.

[10] Yash TL, Dirksen R, Hartly GJ. Antinociceptive effect of intrathecally injected cholinomimetic drugs in the rat and cat. Eur J Pharmacol 1985;117(1):81-8. 
[11] Pandey V, Mohindra BK, Sodhi GS. Comparative evaluation of different doses of intrathecal neostigmine as an adjuvant to bupivacaine for postoperative analgesia. Anesth Essays Res 2016;10 (3):538-45.

[12] Bouaziz H, Tong C, Eisenach JC. Postoperative analgesia from intrathecal neostigmine in sheep. Anesthesia Analgesia 1995;80(6):1140-4.

[13] Hood DD, Eisenach JC, Tuttle R. Phase 1 safety assessment of intrathecal neostigmine methyl sulphate in human. Anaesthesiology 1995;82(2):33143.

[14] Chung CJ, Sukin J, Park HS, et al. The efficacy of intrathecal neostigmine, morphine and their combination for post caesarean section analgesia. Anaesth Analg 1998;87(2):341-6.

[15] Owen MD, Ozsarac O, Sahin S, et al. Low-dose clonidine and neostigmine prolong the duration of intrathecal bupivacaine-fentanyl for labor analgesia. Anaesthesiology 2000;92(2):361-6.
[16] Kaushal D, Singh V, Abbas H, et al. Caudal bupivacaine - neostigmine for perioperative analgesia in paediatric patients undergoing infraumbilical surgery: a prospective, randomized, double blind, controlled study. The Internet Journal of Anesthesiology 2009;21(1):1-7.

[17] Harjai M, Chandra G, Bhatia VK, et al. A comparative study of two different doses of of epidural neostigmine co-administered with lignocaine for postoperative analgesia and sedation. Research paper, Journal of Anesthesiology and Clinical Pharmacology 2010;26(4):461-4.

[18] Yoganarasimha N, Raghabendra TR, Radha MK. A clinical study of perioperative effectiveness of adjuvant neostigmine with intrathecal bupivacaine for lower abdominal surgeries. Journal of Dental and Medical Sciences 2012;2(3):35-9. 